\title{
Deterioration of CLT under Humid and Dry Cyclic Climate
}

\author{
Shiro Nakajima ${ }^{1}$, Yoshihei Sakabe ${ }^{2}$, Seiya Kimoto $^{3}$ and Yoshinori Ohashi ${ }^{4}$ \\ ${ }^{1}$ Department of Architecture and Urban Design, Faculty of Regional Design, Utsunomiya University, \\ 7-1-2 Yoto, Utsunomiya City, Tochigi Pref., Japan, s-nakajima@cc.utsunomiya-u.ac.jp. \\ 2 Japan CLT Association, 2-15-5 Higashi-Nihonbashi, Chuo-ku, Tokyo Met. Japan, y.sakabe@clta.jp. \\ ${ }^{3}$ Technology Research Institute, Mitsui Home Co.Ltd., 2-1-1 Nishi-Shinjuku, Sinjuku-ku, Tokyo \\ Met., Japan, s-kimoto@mitsuihome.co.jp. \\ ${ }^{4}$ Hokkaido Research Organization, Forest Products Research Institute, 1-10 Nishi-Kagura, Asahikawa \\ City, Hokkaido, Japan, ohasi-yosinori@hro.or.jp.
}

\begin{abstract}
Cross laminated timber (CLT) are composed of longitudinal layers and cross layers. And as the laminations of the adjoin layers are glued orthogonally deterioration of the laminations such as check and shake and delamination can be rather frequently come out when CLT is exposed to humid and dry cyclic climate. In Japan more than 100 CLT buildings have been constructed and the number of CLT building is increasing. In some buildings the CLT is designed as to be the exterior members and exposed to the outdoor climate. Several CLT buildings that have CLT as exterior members was investigated to make clear what was ongoing on the CLT panels exposed to outdoor climate. Remarkable check and shake, warp and delamination was observed for the CLT in some of the investigated buildings. To bring out the mechanism of the distortion of CLT under humid and dry cyclic climate and to give a solution to prevent deterioration of CLT a series of laboratory tests were conducted. The CLT panels were set in a climate chamber and exposed to a humid and dry cyclic climate. And the moisture content and the movement of the laminations of CLT were measured. The movement was affected by the species of the laminations and also by the direction of the surface, sap-side or heart-side. And the film forming type painting worked well as to prevent the deterioration and the penetrating type painting could slightly reduce the deterioration.
\end{abstract}

Keywords: CLT, Humid and Dry Cyclic Climate, Delamination, Movement, Species.

\section{Introduction}

In Japan more than 100 CLT buildings have been constructed and the number of CLT buildings is increasing. In some buildings the CLT is designed as to be the exterior members and exposed to the outdoor climate. And even not exposed to the outdoor climate the surface of CLT in many buildings is exposed to the indoor climate.

Cross laminated timber (CLT) are composed of longitudinal layers and cross layers. And the laminations of the adjoin layers are glued orthogonally. Wood has different swelling and shrinkage ratio for tangential direction and radial direction. It is commonly known that the swelling and shrinkage ration of the tangential direction is approximately two times larger than that of the radial direction. The layer arrangement of CLT cause uneven swelling and shrinkage between the adjoin layers particularly under humid and dry cyclic climate. Oshima, A. (2017) indicated that this uneven swelling and shrinkage between the adjoin layers occasionally cause distortion or deformation of the laminations such as check and shake, warp and delamination. 
Lepage, R.T.M. (2012) measured the response of CLT under changing moisture conditions and also simulated the response. CLT produced in Japan are in most cases composed of Japanese species. And there is limited knowledge for the distortion of CLT composed Japanese species. To find a solution to reduce the distortion of CLT the mechanism of the distortion of CLT laminations under humid and dry cyclic climate should be clarified. A series of tests were carried out to estimate the mechanism of distortion of the CLT and to evaluate the capability of surface coating or surface painting against the distortion prevention.

\section{Distortion of CLT Exposed to Outdoor or Indoor Climate}

Several CLT buildings was investigated to have knowledge of the conditions of the CLT panels exposed to the outdoor or indoor climate. The buildings were investigated 2 to 3 years after their completion. Remarkable check and shake, warp and delamination were observed in some of the CLT panels exposed to the outdoor climate and check and shake were also observed in some of the CLT panels exposed to the indoor climate.

Figure 1 shows a bicycle parking space constructed with CLT panels for their walls and roofs. To protect the CLT panels from the sunshine and rain the panels were painted by some impregnated paint designed to protect wood from the outdoor climate. A certain number of check and shake was observed at the bottom of the wall panels and at the roof panels. And warp and delamination were also observed at the edge of the roof panels. The moisture, rain drop and sunshine (i.e. ultra-violet wave) may have caused these distortions.
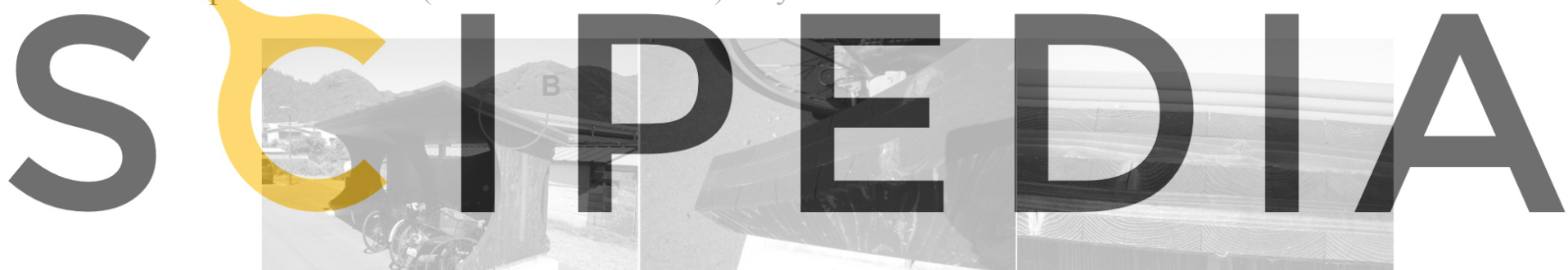

Register for free at https//ww.scipedia.com to download the version without the watermark

Figure 1. Deformation of CLT exposed to outdoor climate (Bicycle parking space).

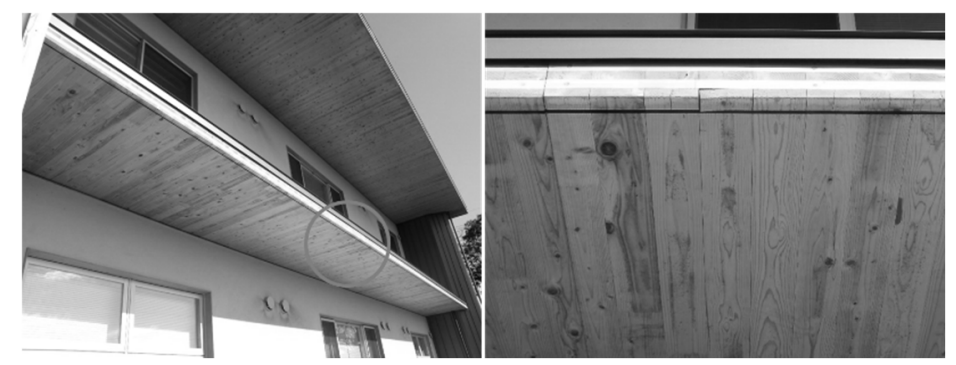

Figure 2. Deformation of CLT exposed to outdoor climate (Eaves of CLT flat roof).

Figure 2 shows the eaves of the CLT flat roof. As the edge of the panels was not covered with weather protecting materials such as steel sheet materials or ceramic boards the edge of the panels was fully exposed to the weathering force. And the panels had damages such as check and shake, warp and delamination. 
Figure 3(a) shows the delamination of the lamination of CLT panels used for the indoor partition wall. Figure 3(b) shows the check and shake and warp of the surface lamination of the CLT panels located close to the outlet of the air conditioner. The shrinkage of the surface of the CLT panels may have caused these types of distortion.

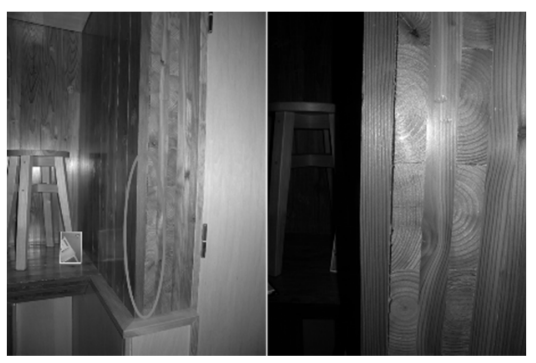

(a) Delamination of the surface lamination.
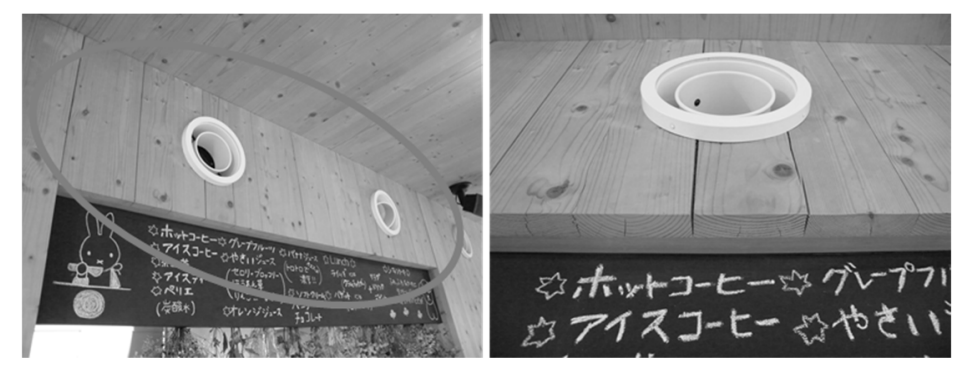

(b) Check and shake of the surface lamination.

Figure 3. Distortion of the CLT panels under indoor climate.

\section{Shrinkage and Swelling of CLT and Glue-Laminated Timber (GLT)}

\subsection{Assumption of the Deformation}

CLT are supposed to shrink as illustrated in Figure 4(a) when it is exposed to a humid to dry climate and the moisture composition of CLT $i$. shrinkage ratio of wood times larger than that o approximately 10 times larger than that of the

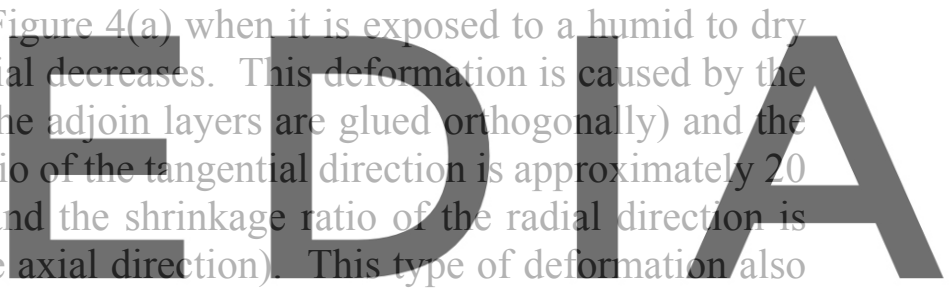
occurs when CLT is exposed to a dry to humid climate.

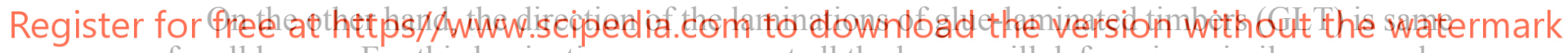
for all layers. For this lamination arrangement all the layers will deform in a similar way under humid and dry climate. And the shrinkage or swelling will be same for all layers as illustrated in Figure 4(b).

Larger Shrinkage

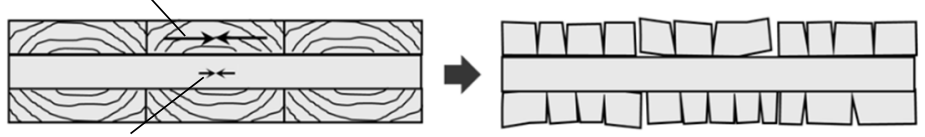

Smaller Shrinkage

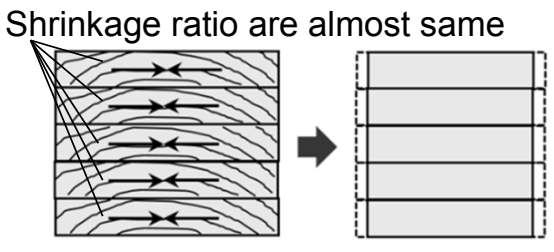

(b) GLT

Figure 4. Deformation of CLT and GLT under humid to dry climate (Cross section).

The response of CLT under its drying process can be modeled as shown in Figure 5. The different shrinkage ratio of the adjoining layers is supposed to be the reason for the check and shake, warp and delamination of the laminations. 

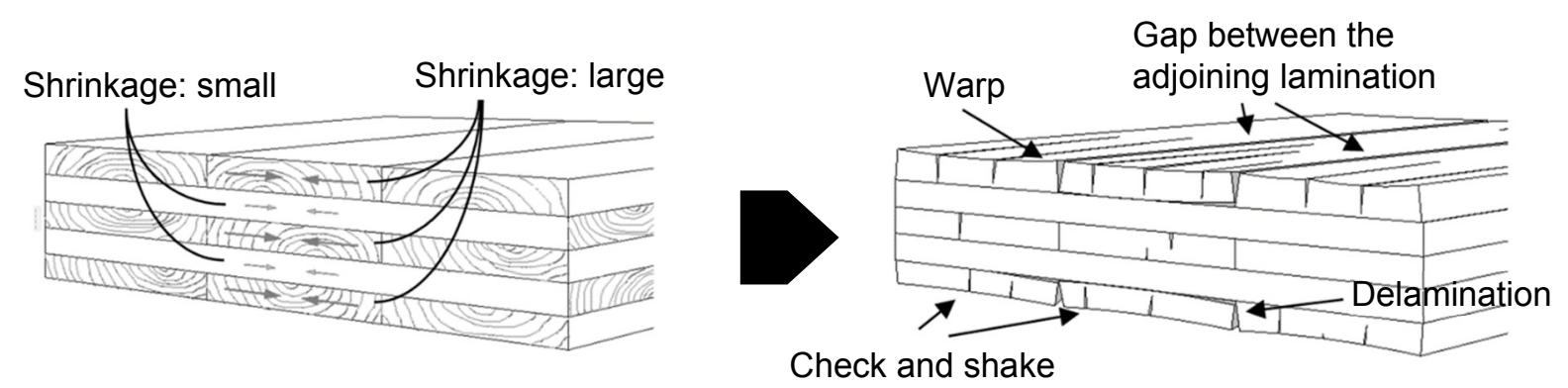

Figure 5. Assumption of the distortion of CLT under its drying process.

\subsection{Testing to Verify the Deformation of CLT and GLT Under Humid and Dry Cyclic Climate}

To verify the assumption that CLT and GLT deform differently when they shrink or swell the deformation of both materials were measured under humid and dry cyclic climate. Figure 6 shows the shape and size of the test specimens and the measuring points of the displacement and moisture content. The deformation of the surface and cross section of both materials were measured by displacement meters and the moisture content of both materials was measured by a moisture meter. The species of the test specimens was Japanese Cedar (cryptomeria japonica) the most popular species for CLT in Japan. The CLT test specimens had five layers and the

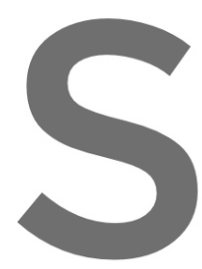
thickness of each layer each layer was $30 \mathrm{~mm}$ for 10 days followed by 3
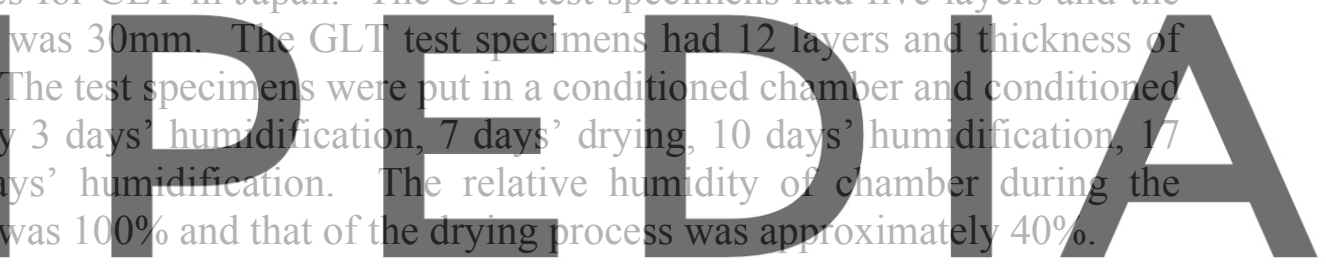

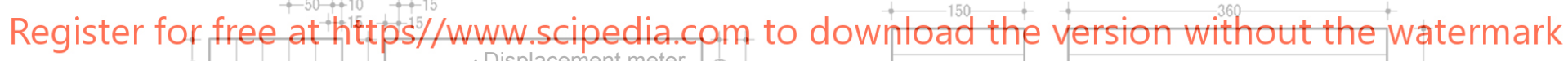

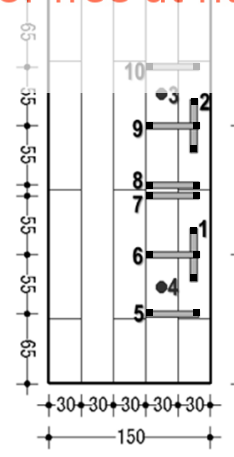

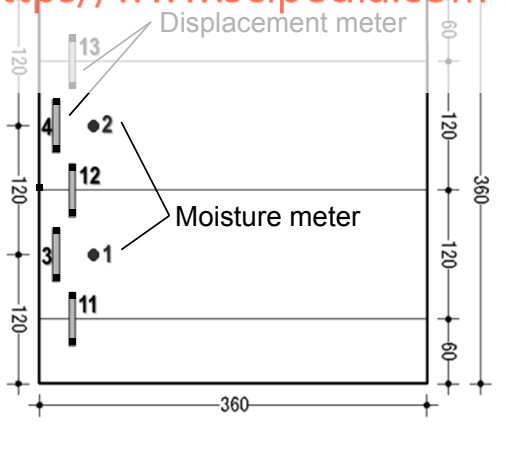

(a) CLT

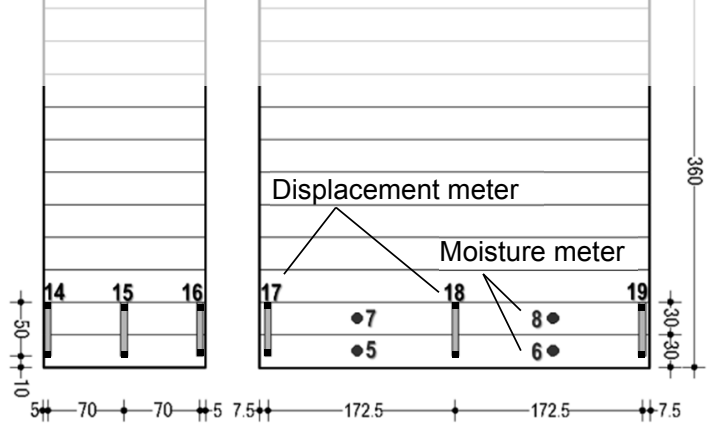

(b) GLT

Figure 6. Shape and size of the test specimens and configuration of the measuring points.

Note: The displacement of CLT was measured at 13 points (the gray bar) and moisture content was measured at 4 points (the gray circle). The local displacement of GLT was measured at 6 points and moisture content was measured at 4 points. 


\subsection{Results and Discussion}

The measured deformation of the cross section of CLT and GLT under humid and dry cyclic climate was measured as shown in Figure 7(a). The narrow lines give the displacement of each measuring point and the thick lines give the average displacement of the measuring points. The deformation of CLT (solid line) is approximately 2 times larger than that of the GLT (broken line). CLT seem to have larger shrinkage and swelling than GLT. The damages of the cross section of CLT and GLT are given in Figure 7(b). Where GLT had only one standing out crack CLT had few cracks on its lamination and gaps between the adjoining laminations.
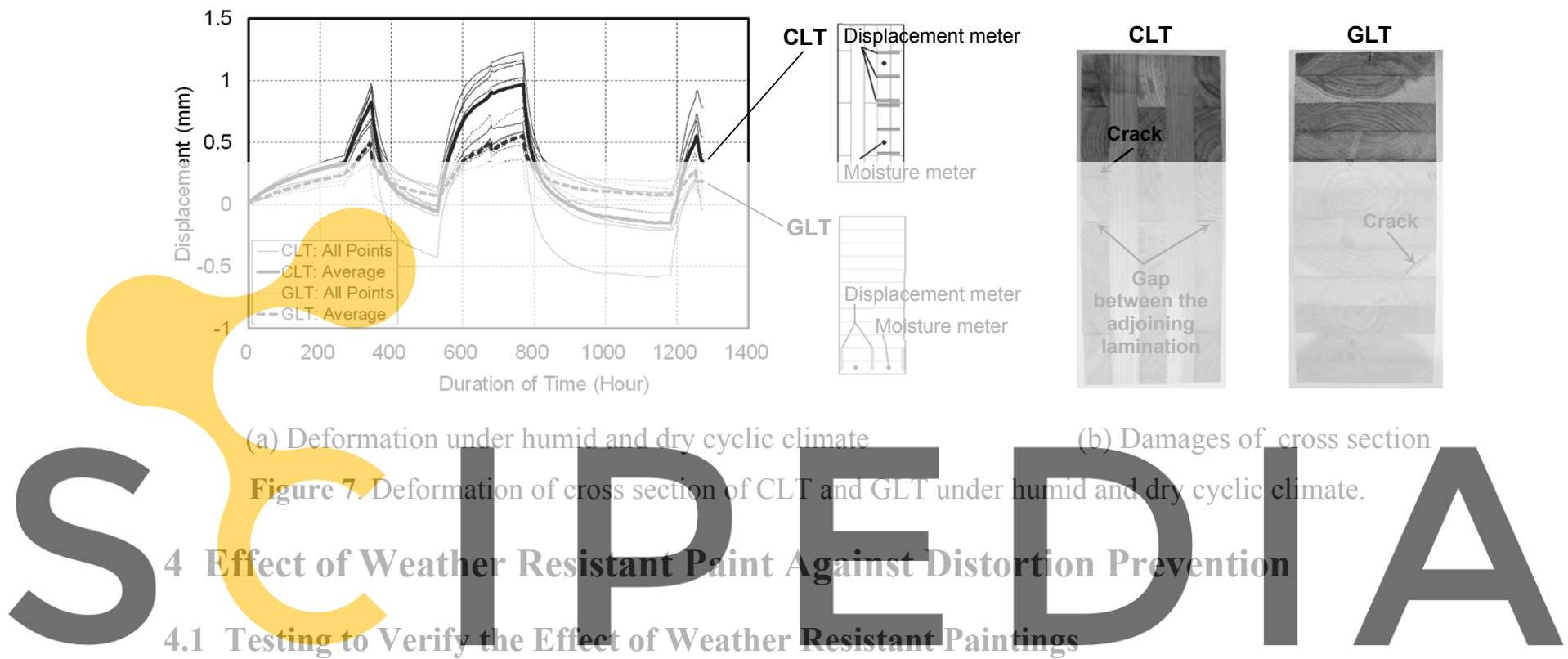

\subsection{Testing to Verify the Effect of Weather Resistant Paintings}

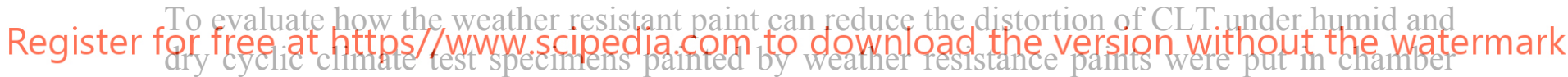

under humid and dry cyclic climate. Four CLT test specimens were tested and three of them were painted by different types of weather resistance paint as shown in Table 1 . The species of the test specimens was Japanese Cedar and the size of the test specimens was $1000 \mathrm{~mm}$ in length, $1000 \mathrm{~mm}$ in width and $150 \mathrm{~mm}$ in depth. The density and initial moisture content of the test specimens are given in Table 1 .

Table 1. Type of weather resistant paints and density and initial moisture content of CLT test specimens.

\begin{tabular}{cccc}
\hline $\begin{array}{c}\text { Name of } \\
\text { test specimens }\end{array}$ & Type of paint & $\begin{array}{c}\text { Density } \\
(\mathrm{kg} / \mathrm{m} 3)\end{array}$ & $\begin{array}{c}\text { Moisture content } \\
(\%)\end{array}$ \\
\hline Control & No painting & 423.5 & 9.3 \\
\hline Painted-1 & Penetrating type 1 & 415.2 & 10.6 \\
\hline Painted-2 & Penetrating type 2 & 418.9 & 13.2 \\
\hline Painted-3 & Film forming type & 417.4 & 11.8 \\
\hline
\end{tabular}

The displacement of the test specimens was measured for 8 points for each test specimen. The in-plane displacement and the out-plane displacement of the laminations were measured as 
illustrated in Figure 8. The measuring points no.1, 2, 5 and 6 are to measure the out-plane deformation of the laminations and the measuring points no.3, 4, 7 and 8 are to measure the inplane deformation of the laminations. And the measuring points no.1,2,3 and 4 are measuring the deformation of the laminations that have their sap-side on the surface side of CLT and the measuring points no.5, 6, 7 and 8 are measuring the deformation of the laminations that have their heart-side on the surface side of CLT.
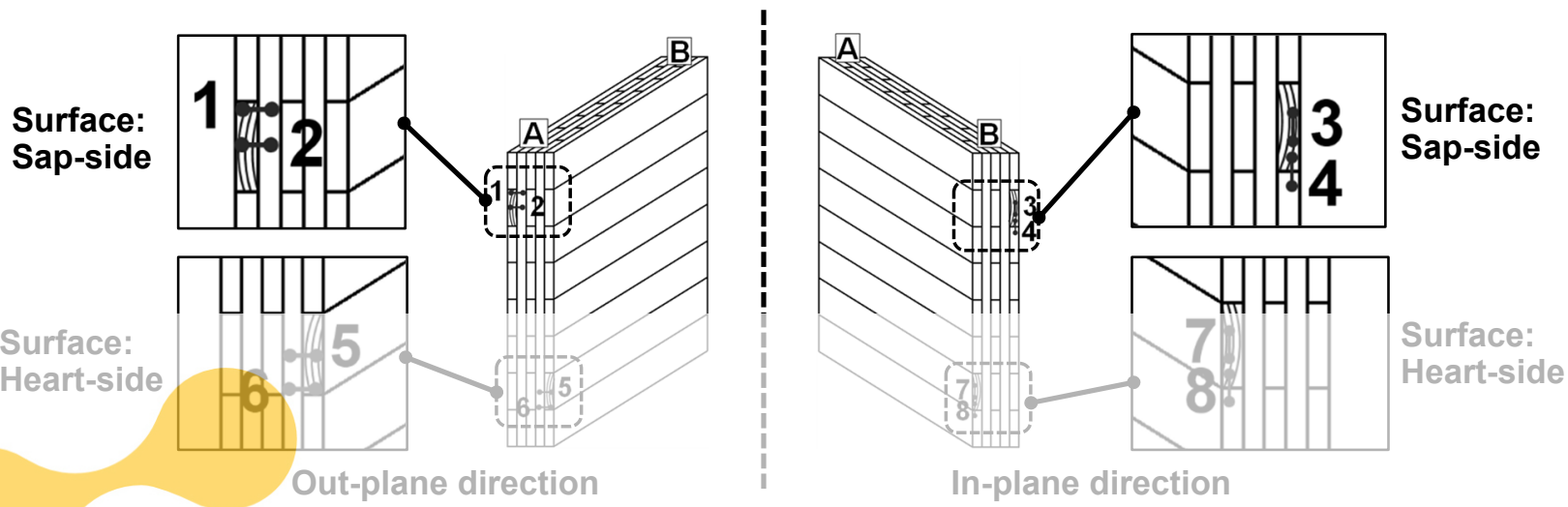

Figure 8. Location of the displacement meters set to measure the displacement of the laminations.

\subsection{Results and Discussion}

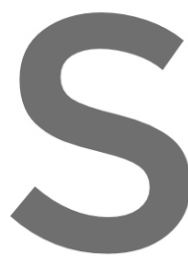

The movement of the given in Figure 9. Figu movement of the CLT painted with film forming penetrating type paintw
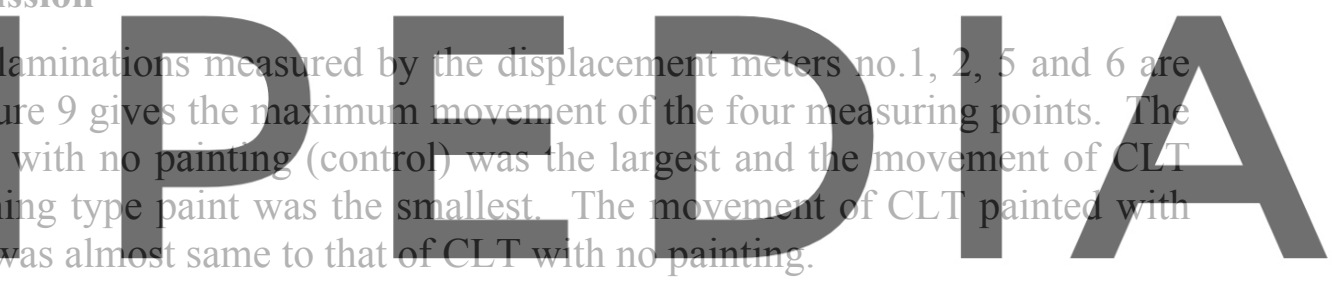

Register for free at https//www.scipedia.Gomonodownloagd the Version without the watermark

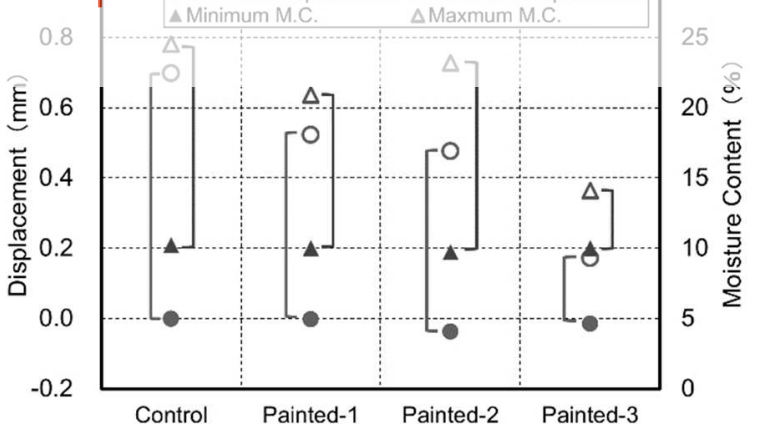

Figure 9. Movement of displacement and movement of moisture content.

Note: Ogives maximum displacement measured by the displacement meters no.1, 2, 5 and 6 and 9 gives minimum displacement. $\Delta$ gives maximum moisture content of the CLTs and $\Delta$ gives minimum moisture content.

The tendency of the moisture content was almost similar to that of the displacement. The moisture content of CLT with no painting had the largest variation and that of CLT painted with 
film forming type paint had the smallest variation. The film forming type paint seems to work well as to reduce the deformation of CLT under humid and dry climate. And the penetrating type paint seem to not work well as to reduce the deformation of CLT.

\section{Effect of the Surface Direction (Sap-Side or Heart-Side)}

\subsection{Testing to Verify the Effect of the Surface Direction}

To verify the effect of the surface direction of the out most layer on the distortion of the laminations CLT composed of sap-side on its surface and CLT composed of heart-side on its surface were tested for their distortion. Figure 10 gives the size and shape of the test specimens and the location of the measuring points for deformation and moisture content. The test specimens were $800 \mathrm{~mm}$ in length, $800 \mathrm{~mm}$ in width and $90 \mathrm{~mm}$ in thickness. And the species of the laminations were Larch (larix kaempferi) or Sakhalin fir (abies sachalinensis). These two species are the northern species in Japan and known as to have relatively high response for moisture content movement. The test specimens were set in a climate that was controlled as to have relative humidity $100 \%$ for 6 days followed by relative humidity $40 \%$ for 12 days and again relative humidity $100 \%$ for another 6 days. The response of the CLT under humid and dry cyclic climate was measured for two directions the out-plane direction and the in-plane direction as shown in Figure 10.
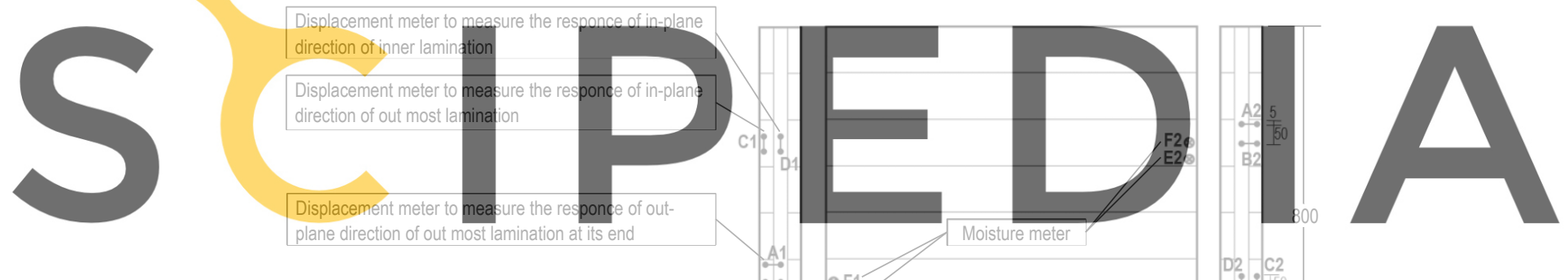

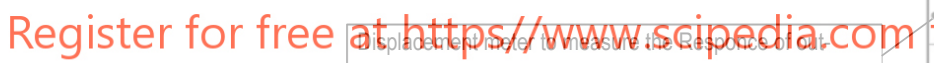
plane direction of out most lamination at its center
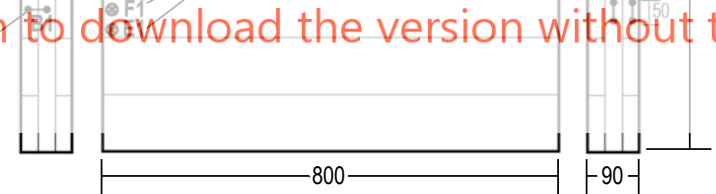

Figure 10. Size and shape of the test specimens, the location of displacement meters and moisture meter.

\subsection{Test Results and Discussion}

The out-plane movement of the out most laminations of Larch CLT under the humid and dry cyclic climate is given in Figure 11(a) and (b). And the in-plane movement of the out most laminations of Larch CLT under the humid and dry cyclic climate is given in Figure 11(c) and (d). The out-plane deformation of the out most laminations was larger than the in-plane deformation. And in general, CLT composed of laminations with heart wood side on the surface side had relatively larger deformation than CLT composed of laminations with sap wood side on the surface side. The test result for Sakhalin fir CLT was almost same to that of Larch CLT. These test results indicate that one solution to reduce the moisture related deformation of CLT is to arrange the out most laminations so as to cover the surface of CLT with the sap wood side of the laminations. 


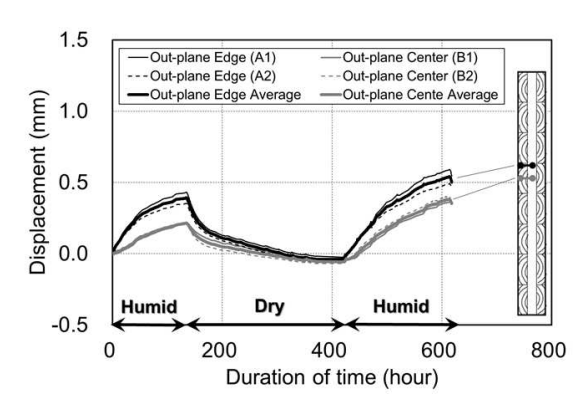

(a) Out-plane direction, Surface sap wood.

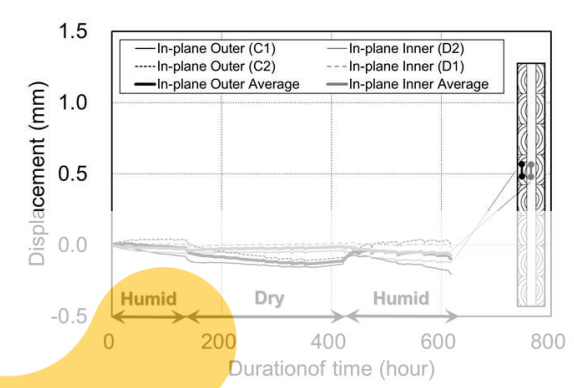

(c) In-plane direction, Surface sap wood.

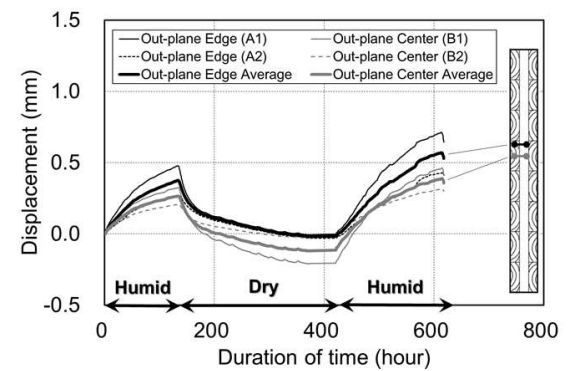

(b) Out-plane direction, Surface heart wood.

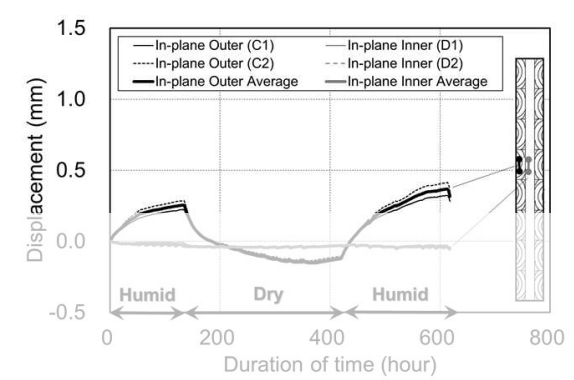

(d) In-plane direction, Surface heart wood.

Figure 11. Response of the CLT under humid and dry cyclic climate (Larch).

\section{Conclusion}

A series of tests werd evaluate the capability

The results are summarize

The deformation
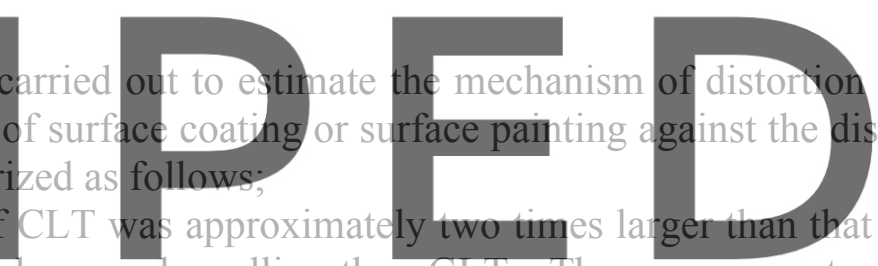

showed larger shrinkage and swelling than GLT. The arrangement of the Tamination si

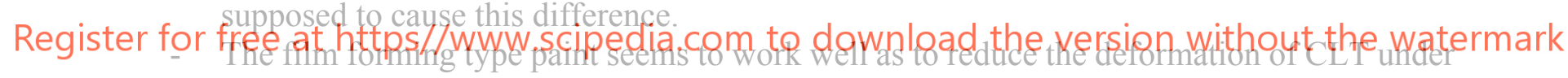

humid and dry climate. And the penetrating type paint seem to not work well as for reducing

the deformation of CLT.

- One solution to reduce the moisture related deformation of CLT is to arrange the out most laminations of CLT so as to cover the surface of CLT with the sap wood side of the laminations.

\section{ORCID}

Shiro Nakajima: http://orcid.org/ 0000-0002-5382-5175

\section{Acknowledgement}

This research was founded by the Taisei Foundation.

\section{References}

Oshima, A. (2017). Survey on durability of timber buildings composed of CLT panels, Bachelor Thesis, University of Utsunomiya, Tochigi, Japan.

Lepage, R.T.M. (2012). Moisture Response of Wall Assemblies of Cross-Laminated Timber Construction in Cold Canadian Climates, PhD Thesis, University of Waterloo, Ontario, Canada. 